\title{
Regulation of Short-Term Associative Memory by Calcium- Dependent Protein Kinase
}

\author{
Louis D. Matzel, ${ }^{a}$ I. Izja Lederhendler, and Daniel L. Alkon \\ Section on Neural Systems, Laboratory of Molecular and Cellular Neurobiology, National Institutes of Neurological \\ Disorders and Stroke, National Institutes of Health, Bethesda, Maryland 20892
}

Neural and behavioral correlates of an associative memory in Hermissenda were examined during induction and/or formation of the memory. Hermissenda recelved either light (conditioned stimulus or $\mathrm{CS}$ ) and rotation (unconditioned stimulus or US) paired (i.e., Pavlovian conditioning), light and rotation unpaired (pseudoconditioning), or no exposure to light and rotation. Following 9 pairings in a $6 \mathrm{~min}$ session, conditioned animals exhibited a contraction of the foot in response to a test CS presented 2 min after the last conditioning trial, whereas pseudoconditioned and untreated animals exhibited a foot extension to the same CS. In addition, both an associative and a nonassociative reduction in light-induced locomotion was observed. To examine neural correlates of this learning within minutes of acquisition, the isolated nervous system of the Hermissenda (containing the visual and vestibular organs) was trained with stimulus conditions identical to those used for the intact animal. Prior isolation and preparation of the nervous system permitted immediate intracellular recording following the final conditioning trial. Relative to pseudoconditioned and untreated animals, the $B$ photoreceptors in conditioned nervous systems were found to have elevated input resistance (inversely related to $\mathrm{K}^{+}$channel conductance and positively related to excitability) and exhibited increased steady-state depolarization in response to the light CS, as well as a prolonged depolarization after the $\mathrm{CS}$ offset. These neural correlates of the associative memory were attenuated if the protein kinase inhibitor $\mathrm{H} 7$ was present in the extracellular bath during conditioning, demonstrating in the reduced preparation that antagonism of protein kinase activity blocks the induction of membrane alterations of identified neurons that correlate with memory storage. In a final experiment, in vitro conditioning was conducted in which discrete light steps were presented paired or unpaired with depolarizing current injected across the B cell soma membrane (to simulate rotation-induced depolarization). A pairing-specific, cumulative depolarization (presumably $\mathrm{Ca}^{2+}$-induced) of the $\mathrm{B}$ cell was observed that was accompanied by, and outlasted by, an increase in membrane resistance that persisted for at

Received Sept. 28, 1989; revised Jan. 19, 1990; accepted Mar. 12, 1990.

This work was conducted as part of the Intramural Research Program of the National Institute of Neurological Disorders and Stroke. We thank Carlos Collin for many helpful discussions and David Lester for a critical review of an earlier version of the manuscript.

a Correspondence should be addressed to Louis D. Matzel, at his present address: Department of Psychology, Rutgers University, Busch Campus, New Brunswick, NJ 08903.

Copyright (C) 1990 Society for Neuroscience $0270-6474 / 90 / 072300-08 \$ 03.00 / 0$ least $10 \mathrm{~min}$. The increase in resistance (but not the cumulative depolarization) was blocked by $\mathrm{H} 7$ and sphingosine, which inhibit the activity and activation, respectively, of protein kinase C (PKC) and calmodulin-dependent protein kinase (CaM kinase). In contrast, HA 1004, an inhibitor of the CAMP-dependent protein kinase, did not block the induction of elevated resistance. These results suggest that regulation of ion channel conductance by PKC and/or CaM kinase is an important early stage in the induction of associative memory in Hermissenda.

Increasing evidence suggests that neuronal excitability may be modulated by protein phosphorylation of ionic channels (e.g., Levitan, 1985; Naito et al., 1988). It has been suggested that persistent changes in protein phosphorylation that outlast the initiating signal may be an important initial stage in the acquisition and storage of memories (Neary et al., 1981; Schwartz and Greenberg, 1987; Lisman and Goldring, 1988; Naito et al., 1988). This combined process has been proposed as an underlying mechanism in the storage of nonassociative (Kandel et al., 1986) and associative memories (Alkon, 1984, 1989), as well as long-term potentiation, or LTP (Malinow et al., 1988), a potential model of vertebrate learning.

In the nudibranch mollusk Hermissenda, several lines of evidence have implicated the second messenger-regulated protein kinase $\mathrm{C}(\mathrm{PKC})$ and/or calmodulin-dependent protein kinase (CaM kinase) in the reduction of ionic currents that appear to mediate associative learning. During acquisition of a light-rotation association (behaviorally indexed by reduced phototaxis and foot contraction in the presence of light), the B photoreceptors of the Hermissenda's eye undergo a transient, depolarization-induced rise in levels of intracellular $\mathrm{Ca}^{2+}$ (Connor and Alkon, 1984). This increase in free $\mathrm{Ca}^{2+}$ results in phosphorylation of specific proteins (e.g., $20 \mathrm{kDa}$ ) in these cells (Neary et al., 1981; Nelson and Alkon, 1989) that have been related to the inactivation of a fast, voltage-dependent $\mathrm{K}^{+}$current $\left(\mathrm{I}_{\mathrm{A}}\right)$ and a slower, $\mathrm{Ca}^{2+}$-dependent $\mathrm{K}^{+}$current $\left(\mathrm{I}_{\mathrm{C}}\right)$. Reduction of these currents decreases conductance across the photoreceptor's membrane and thereby increases the cell's resistance to current and, hence, its excitability, which is thought to bias the neural network toward new behavioral responses.

In the Hermissenda's eye (containing $3 \mathrm{~B}$ cells and $2 \mathrm{~A}$ cells), phosphorylation of the $20 \mathrm{kDa}$ phosphoprotein has been found to increase at least 2-fold in associatively trained animals (Neary et al., 1981). Further studies have indicated that this protein is phosphorylated in vitro by both PKC and CaM kinase. Moreover, recent work has found that direct iontophoretic injection of the $20 \mathrm{kDa}$ protein (Nelson et al., 1990), of phorbol ester, an 
activator of PKC (Alkon et al., 1986; Farley and Auerbach, 1986), or of PKC itself (Farley and Auerbach, 1986; Alkon et al., 1988), all result in a reduction of $I_{A}$ and $I_{C}$ that resembles the reduction normally occurring during associative learning.

In the present experiments, we sought to determine the extent to which PKC and/or CaM kinase regulated the initial storage of short-term (2-10 $\mathrm{min}$ ) conductance changes indicative of associative memory, and we correlated these neuronal changes with associative behavioral responses. In contrast to earlier reports that activators of PKC and CaM kinase induced conductance changes that mimic those occurring during associative learning, in the present experiments we directly observed the effects of inhibition of protein kinase activation on the acquisition of associative memory. Intact, semi-intact, and in vitro conditioning procedures were employed so that both behavior and protein kinase activity could be examined in parallel. As we were specifically concerned with the induction of the associative memory (as opposed to its maintenance), the conditioning procedures were specifically designed to provide the opportunity to monitor behavioral and cellular responses during and/ or immediately after conditioning.

\section{Materials and Methods}

Animals. Hermissenda crassicornis $(0.65-1.10 \mathrm{gm})$ were obtained from Sea Life Supply Co. (Sand City, CA). Animals were individually housed in 50-ml flow-through tubes suspended in refrigerated artificial sea water (ASW) kept at $12^{\circ} \mathrm{C}$. The animals were maintained on a $12 \mathrm{hr} / 12 \mathrm{hr}$ light/dark cycle. The intensity of the light where it reached the surface of the water was $20 \mu \mathrm{W} \times \mathrm{cm}^{-2}$ and was filtered through yellow acetate (Visual Systems, Rockville, MD, stock 13-01053). All experimental manipulations were conducted during the middle $10 \mathrm{hr}$ of the light cycle.

Behavioral training and testing. After at least $5 \mathrm{~d}$ in our laboratory, animals were placed in individual tracks $(15.0 \times 0.9 \times 0.6 \mathrm{~cm})$ milled in clear Plexiglas. The tracks were filled with refrigerated ASW and covered by a clear Plexiglas lid. A field of 16 tracks could be mounted on a Lab Line Instruments shaker (model 4600), which was calibrated to produce a $1000 \mathrm{rpm}, 4.0-\mathrm{mm}$-displacement orbital shaking motion that served as the unconditioned stimulus (US). The shaker was housed in a sound- and light-proof incubator that maintained a temperature of $12^{\circ} \mathrm{C}$. Sixty centimeters above the tracks was an electronic shutter through which the emitted light from a $21.5 \mathrm{~V}, 150 \mathrm{~W}$ (nominal) tungsten halogen projector lamp could be passed. With the shutter open, the output of the bulb was adjusted so that the intensity of the light that reached the tracks was $600 \mu \mathrm{W} \times \mathrm{cm}^{-2}$. This light served as the conditioned stimulus (CS). Animals that received paired $(n=18)$ or unpaired $(n=18)$ CSUS presentations were placed in individual tracks where they remained in a darkened incubator for $10 \mathrm{~min}$. Paired (i.e., associatively conditioned) animals then received 9 CS-US pairings at 40 -sec intervals. A pairing consisted of a $4 \mathrm{sec}$ light CS presentation that coterminated with $3 \mathrm{sec}$ of rotation. Animals that received unpaired training were exposed to these same stimuli on an explicitly unpaired schedule of alternating CSs and USs at 20-sec intervals. A third group, designated as "naive" $(n=18)$, were placed in tracks but simply maintained in darkness for $10 \mathrm{~min}$. After the last stimulus presentation (or the $10 \mathrm{~min}$ of dark adaptation for naive animals), the field of tracks was placed on a stand (still in darkness) that allowed the foot of the animals to be videotaped (during a light CS) by a Panasonic WV-CD 50 video camera fitted with

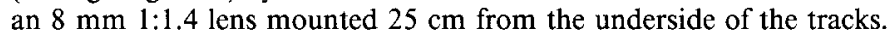
Two and 4 min after the end of the training session, the light CS was again presented, each time in the absence of rotation. Within $100 \mathrm{msec}$ of the onset of the light, and again $100 \mathrm{msec}$ prior to its offset, the length of the animal's foot was measured. Normally (prior to conditioning), these animals exhibit a foot extension when a light is presented in periods of darkness. However, it has been reported that after pairings of light and rotation, the light elicits foot contraction, a clinging response normally elicited by rotation [Lederhendler et al., 1986; Matzel et al., in press (b)]. In addition, rate of locomotion was measured during the 10 sec light presentations, as general decreases in locomotor behavior in the presence of light have also been reported following light-rotation pairings [Matzel et al., in press (a)]. The videotapes were scored by an observer who had no knowledge of the treatment conditions of the various groups. This experiment was conducted in several balanced replications.

Training of intact nervous systems. In order to observe neural correlates of memory within minutes of conditioning, it was necessary to prepare the nervous system of the Hermissenda for electrophysiological analysis prior to the conditioning session. The nervous system (which includes the visual and vestibular organs) was dissected out of the $\mathrm{Her}$ missenda, secured to a glass slide with several pins, and treated with 1 $\mathrm{mg} / \mathrm{ml}$ protease (Sigma, P-8038; dissolved in ASW) for $6 \mathrm{~min}$ at $22^{\circ} \mathrm{C}$. Proteolysis of the connective tissue sheath facilitated subsequent microelectrode penetration. Dissection was conducted under as low a level of light as was possible. Following proteolysis, a single nervous system was placed in an ASW-filled dish which was then secured to a shaker in a darkened incubator in which the temperature was maintained at $18^{\circ} \mathrm{C}$. Three groups of nervous systems $(n \mathrm{~s}=6)$ were subjected to the same conditioning regimens (paired, unpaired, naive) that were previously described for the whole animal. A fourth group of animals $(n=$ 6) was also trained with paired light and rotation, but $100 \mu \mathrm{M}$ of $\mathrm{H} 7$ (Sigma, I-0260), a compound that inhibits the catalytic activity of protein kinases (Hidaka et al., 1984), was added to the ASW bath after proteolysis and for the remainder of the experiment. At the end of the training session, the medial B cell was impaled with a glass microclectrode, and input resistance and responses of the B cell to light were measured $1 \mathrm{~min}$ after impalement. Impalement was conducted under dim red light $(630 \mathrm{nM})$ that resulted in a depolarization of the $B$ cell of approximately $10 \%$ of the magnitude elicited by the white light test stimulus, with no measurable long lasting depolarization (LLD) measured (in all experiments) $20 \mathrm{sec}$ after the offset of the light. Cells that were not successfully impaled within $5 \mathrm{~min}$ of the end of training were discarded.

Electrophysiology. Electrophysiological recordings were obtained using previously published methods (e.g., West et al., 1982). Microelectrodes filled with $3 \mathrm{M} \mathrm{KCl}$ had a resistance of 15-30 M $\Omega$ and were connected by a chloridized silver wire to the input stage of a high impedance amplifier. Voltage responses were acquired via oscilloscope photography and on a Brush pen recorder. To measure input resistance, 300 -msec positive and negative current pulses $(0.2,0.4$, and $0.6 \mathrm{nA})$ were applied through the recording electrode using a balanced bridge circuit. The voltage response was measured $250 \mathrm{msec}$ after the onset of the current. An unfiltered white light (focused on the nervous system) of the same intensity as the light CS used for behavioral training/testing was used to assess the B cell light response. All experiments were conducted at $18^{\circ} \mathrm{C}$

In vitro conditioning. The nervous system of the animals was removed, and all impulse activity and synaptic interactions of the medial $\mathrm{B}$ cell were eliminated by severing the cell's axon approximately $60 \mu \mathrm{m}$ from the soma. This procedure produces no measurable changes of lightinduced voltage responses (Alkon, 1979). Following dissection, the preparation was subjected to proteolysis as described above. Following impalement with a microelectrode, the cell was maintained in the dark for $10 \mathrm{~min}$. Input resistance was then measured, and conditioning was begun. Each cell received either paired or unpaired presentations of a $4 \mathrm{sec}$ light exposure and $3 \mathrm{sec}$ of positive current injection (approximately $1-2 \mathrm{nA}$ ) that was sufficient to depolarize the cell $20-25 \mathrm{mV}$ from its normal rest of -40 to $-50 \mathrm{mV}$. This level of depolarization is sufficient to partially activate a voltage-dependent $\mathrm{Ca}^{2+}$ conductance even in the absence of light (Alkon et al., 1984; Farley, 1988). For the paired condition, 9 light-current injections occurred at 40-sec intervals. For the unpaired condition, the light and current injections alternated at 20-sec intervals. Pairings of light and depolarizing current were intended to simulate the effects on the B cell of pairings of light and rotation in the intact animal. This procedure has been previously shown to produce cumulative depolarization (Alkon, 1980), an increase in input resistance, and a prolonged LLD in the B cell. When employed in an intact animal, it has also been found to evoke an associative behavioral change in response to light (Farley et al., 1983).

These preparations were maintained in 1 of 4 bathing solutions: ASW (paired, $n=6$; unpaired, $n=5$ ), ASW with $100 \mu \mathrm{M} \mathrm{H} 7$ added (paired and unpaired, $n \mathrm{~s}=5$ ), ASW with $100 \mu \mathrm{M}$ sphingosine (Sigma, S-3263) added (paired, $n=6$; unpaired, $n=5$ ), or ASW with $100 \mu \mathrm{M}$ of the cAMP-dependent kinase inhibitor HA1004 (Seikagaku, 120804) added (paired and unpaired, $n s=6$ ). While $\mathrm{H} 7$ inhibits the catalytic activity of activated PKC and CaM kinase, sphingosine competes with diacylglycerol for PKC activation, although it has also been shown to function 

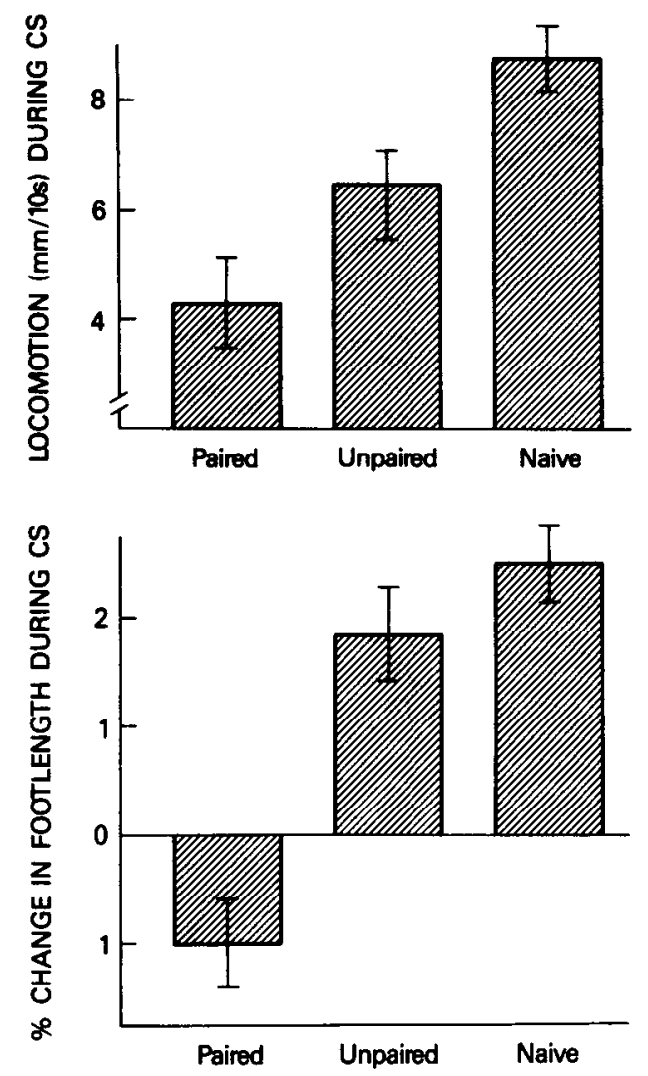

Figure 1. Mean response to $10-\mathrm{sec}$ test light by animals previously exposed to paired light and rotation ( 9 trials), unpaired light and rotation, or no light and rotation. Responses were measured 180 and 360 sec after the end of the conditioning session and have been collapsed across the 2 times. The top panel illustrates the rate of locomotion during the light and the bottom panel the percent change in the length of the animals' foot during the middle $9.8 \mathrm{sec}$ of light. Paired light and rotation resulted in generally lower rates of locomotion and a foot contraction relative to the unpaired or naive groups. Note a nonassociative component to the locomotion response absent from the footlength response. Brackets indicate standard error.

as a calmodulin antagonist (Jefferson and Schulman, 1988). In contrast, $\mathrm{HAl} 1004$, although chemically similar to $\mathrm{H} 7$, is relatively ineffective against PKC but is a potent inhibitor of the cAMP-dependent protein kinase (i.e., A Kinase; Hidaka et al., 1984). The bathing solution was exchanged at approximate $5 \mathrm{~min}$ intervals throughout the experiment.

Statistical analysis. Single- or multi-factor ANOVAs were conducted for each experiment. Follow-up tests based on the error term of the overall ANOVA (i.e., planned comparisons; Keppel, 1982) were used for comparison of individual means.

\section{Results}

\section{Behavior}

Figure 1 depicts the behavioral responses to light following paired, unpaired, or no exposure to light and rotation. The configuration of the foot during the CS (Fig. 1, bottom panel) was influenced by treatment $[F(2,40)=5.85, p<0.01]$. Two minutes following the end of the training session, paired exposure to light and rotation resulted in a foot contraction in the presence of light, whereas unpaired or no exposure resulted in a foot extension. The paired group differed from each of the nonassociative control groups $[F(1,40) \leq 6.23, p<0.05]$. The control groups, however, did not differ from one another $(F=0.44)$.

From the locomotion data, a significant effect of treatment was observed $[F(2,51)=7.52, p<0.001]$. Paired exposure to light and rotation resulted in significantly less locomotion in the

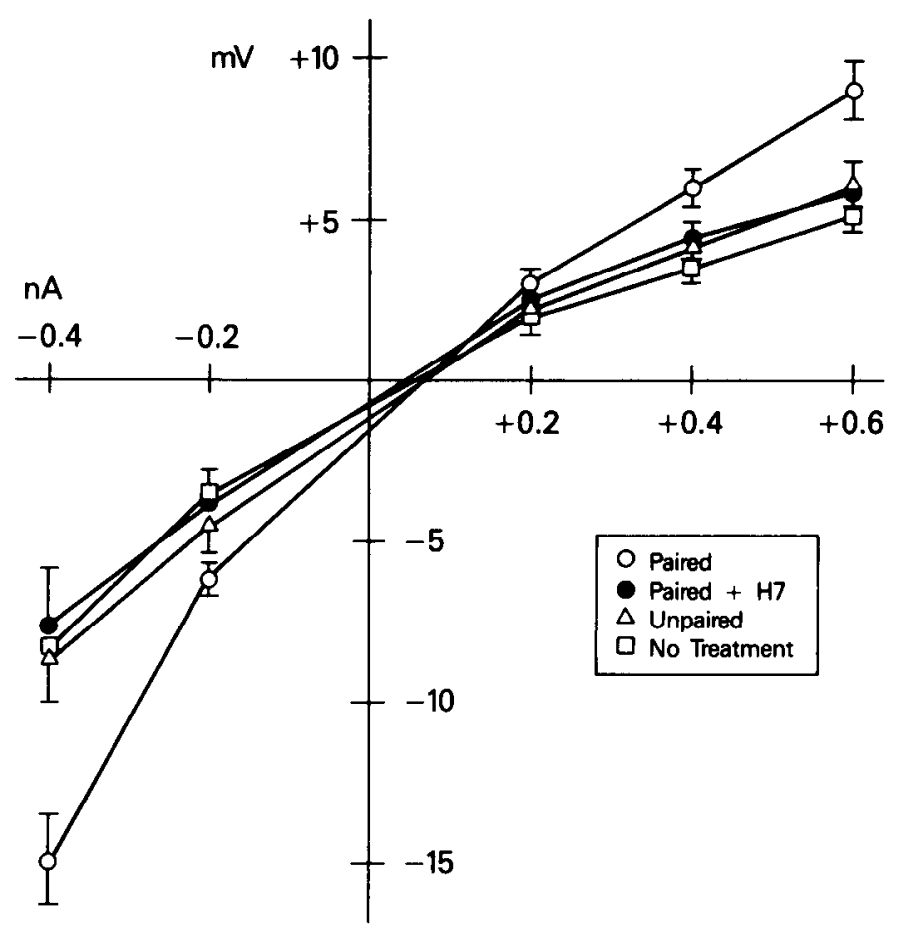

Figure 2. A current-voltage plot of the medial B photoreceptor approximately $5 \mathrm{~min}$ after paired, unpaired, or no exposure of the isolated nervous system to light and rotation. Equivalent current injections result in an elevated voltage response (i.e., increased resistance) if the animals were exposed to light-rotation pairings (i.e., associatively conditioned), as indicated by the open circles. However, the increase in resistance was blocked if $100 \mu \mathrm{M}$ of $\mathrm{H} 7$, a PKC and CaM kinase antagonist, was present in the bathing solution during the training session (filled circles). Brackets indicate standard error.

presence of the light relative to naive animals $[F(1,51)=15.05$, $p<0.001]$. However, paired training resulted in only marginally slower locomotion than did unpaired training $[F(1,51)-3.47$; $p<0.10$ ]. Moreover, unpaired training resulted in marginally slower rates of locomotion relative to naive animals $[F(1,51)=$ $4.06, p<0.10$ ]. These results suggest that $2 \mathrm{~min}$ following conditioning, there is both an associative and a nonassociative influence of conditioning on the rate of locomotion.

The present results, like prior work [Matzel et al, in press (b)], suggest that foot contraction and decreased locomotor behavior are independent responses to the CS following CS-US pairings. As in a previous report by Crow (1983), we have found evidence for a nonassociative reduction of locomotion shortly ( 2 min) after conditioning (cf., Grover et al., 1987). No nonassociative influence on locomotion is typically observed at retention intervals of $1 \mathrm{hr}$ (e.g., Crow, 1983) or longer [Crow and Alkon, 1978; Matzel et al., in press (a)]. However, the present results indicate both an associative and a nonassociative component to the short-term locomotor response. In addition, foot contraction (an active response) developed as a short-term conditioned response that did not appear to be influenced by nonassociative factors.

\section{Conditioning of intact nervous systems}

Figure 2 illustrates the voltage responses of the B cell soma membranc to current injection 4-8 min following conditioning. At that time, no differences in the resting membrane potential were detected $(F=0.86)$. However, membrane resistance was 

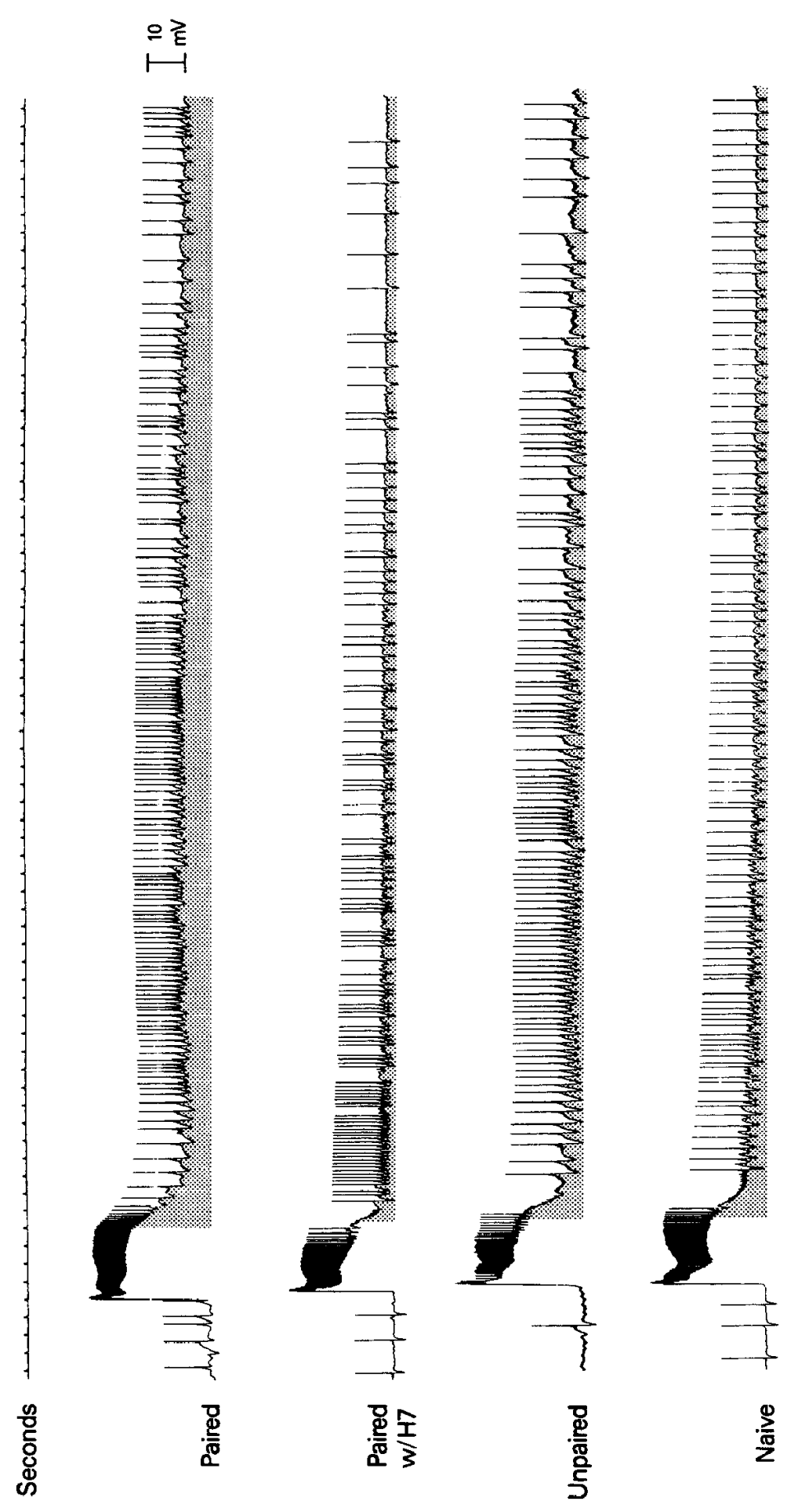

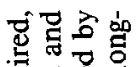

늘

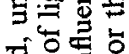

递员

总䡒

牙要总

要范

플 尊要

焉完

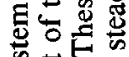

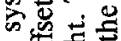

包实整

爮吉

牙芯

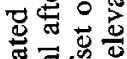

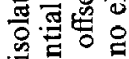

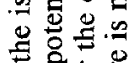

to o o

整总呵

원

on o

产 웡

응 뭉

녕 苋导

는 흥

过正点

웅혀ㅇㅝㅗ

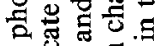

象总 동

통.

혼

密要要

要

के

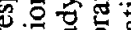

要 战

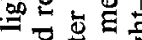

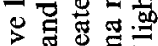

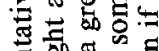

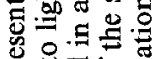

궁.

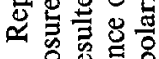

施要递

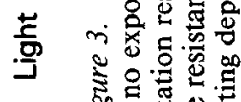

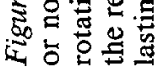



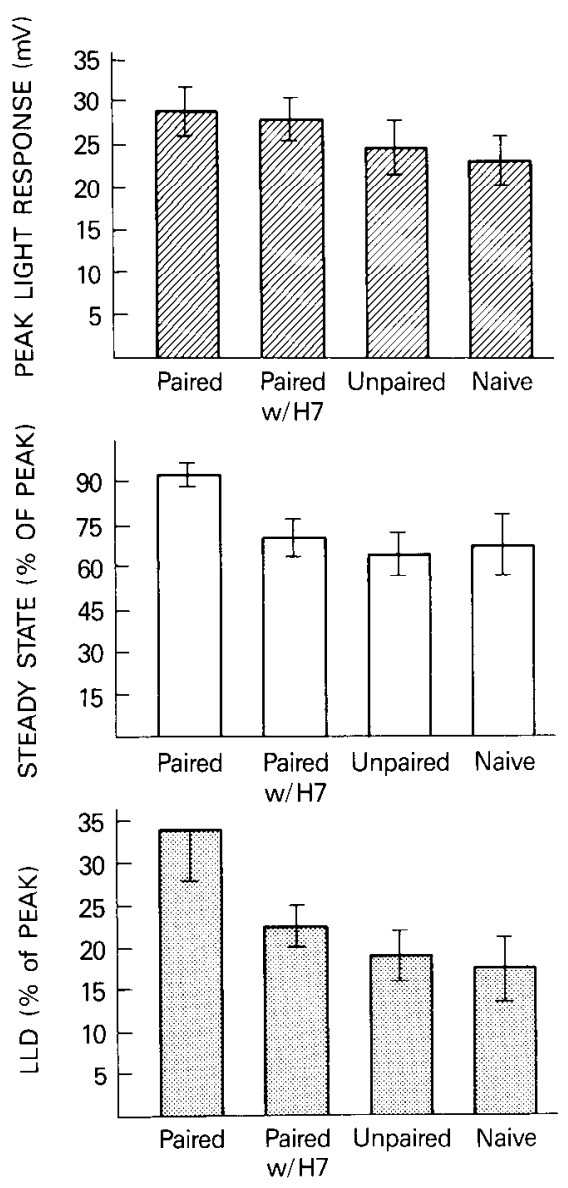

Figure 4. Group means of 3 responses of medial B cells to a 4-sec light taken approximately $5 \mathrm{~min}$ after paired, unpaired, no exposure of the isolated nervous system to light and rotation, or paired exposure with $\mathrm{H} 7$ present in the ASW bath. The peak light response is illustrated in the top panel, the steady-state light response (as a percentage of the peak) in the middle panel, and the level of depolarization (as percentage of the peak) in the bottom panel 20 sec after the offset of the light. Whilc the peak response did not differ, the steady-state and the long-lasting depolarization was enhanced in the B cells exposed to pairings, provided that $\mathrm{H} 7$ was not in the bath during conditioning.

significantly affected by treatment $[F(3,20)=3.62, p<0.05]$. Animals that received paired light and rotation were found to have higher membrane resistance than did animals that received unpaired, no exposure, or paired exposure to those stimuli in the presence of the protein kinase inhibitor $\mathrm{H} 7[F(3,20) \geq 6.14$, $p<0.05$ ]. These latter 3 groups did not differ among themselves $(F \leq 0.30)$.

Representative responses of the B photoreceptor to a 4-sec light flash are depicted in Figure 3. The peak light response did not differ between groups $(F=0.33)$. In contrast, the LLD, measured as the percent of the peak light response $20 \mathrm{sec}$ after the offset of the test light, differed between groups $[F(3,20)=$ $3.22, p<0.05]$. Comparisons of individual means indicated that paired training resulted in a greater LLD than did unpaired or no training, or paired training in the presence of $\mathrm{H}][F(1,20)$ $\geq 5.62, p<0.05$ ]. These latter 3 groups did not differ among themselves $(F \leq 0.83)$. The steady-state light response of paired animals, measured at asymptote approximately $2 \mathrm{sec}$ after the onset of the light and converted to a percentage of the peak light response, was also greater than that exhibited by unpaired and

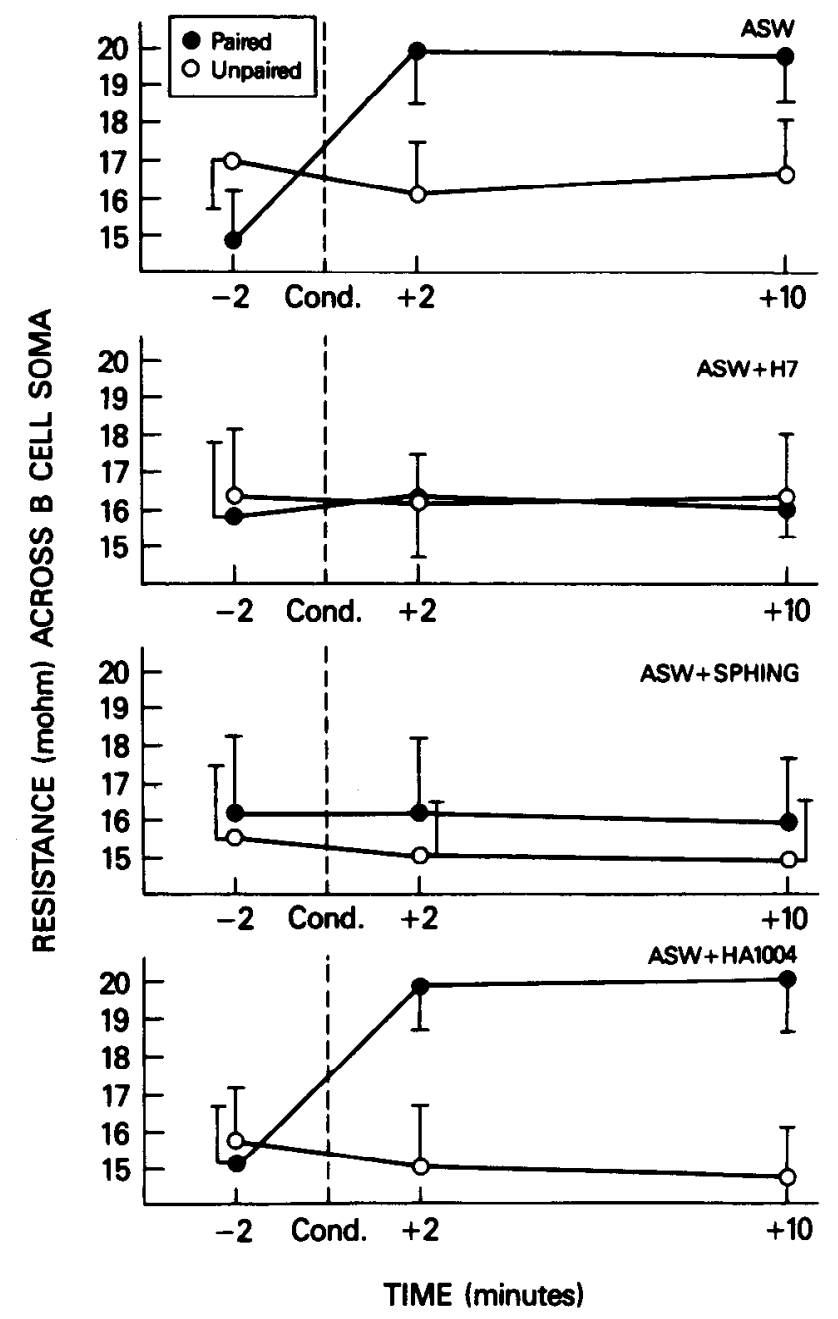

Figure 5. Group means of resistance $2 \mathrm{~min}$ before, $2 \mathrm{~min}$ after, or 10 min after either paired (filled circles) or unpaired (open circles) exposure of the isolated B photoreceptor to light and depolarizing current. This procedure mimics the effects on the $\mathrm{B}$ cell of light-rotation presentations in the intact nervous system. These treatments were conducted with either ASW, H7, sphingosine, or HA1004 (all $100 \mu \mathrm{M}$ ) present in the bathing solution. Although none of the latter 3 compounds affected the resting membrane potential or basal levels of resistance, $\mathrm{H} 7$ and sphingosine, which inhibit the activity and activation (respectively) of PKC, blocked the increase in resistance that occurred with conditioning. This was not true of HA1004, a cAMP-dependent protein kinase inhibitor.

untreated animals $[F(1,20) \geq 4.36, p<0.05]$ and was marginally greater than in paired animals in which $\mathrm{H} 7$ was present in the bath $[F(1,20)=3.35, p<0.10]$. Group means for these light responses are illustrated in Figure 4.

\section{In vitro conditioning}

Like presentations of light paired with rotation to the isolated nervous system, pairings of light and depolarizing current to the isolated $B$ cell resulted in an increase in resistance if the pairings occurred in normal ASW, as depicted in the top panel of Figure 5. This effect was blocked by $\mathrm{H} 7$ (second panel), presumably via inhibition of the catalytic activity of PKC and/or CaM kinase, or if the activation of these kinases was blocked by sphingosine (third panel). However, the cAMP-dependent kinase inhibitor HA1004 was ineffective in blocking the effects of this in vitro conditioning procedure. 


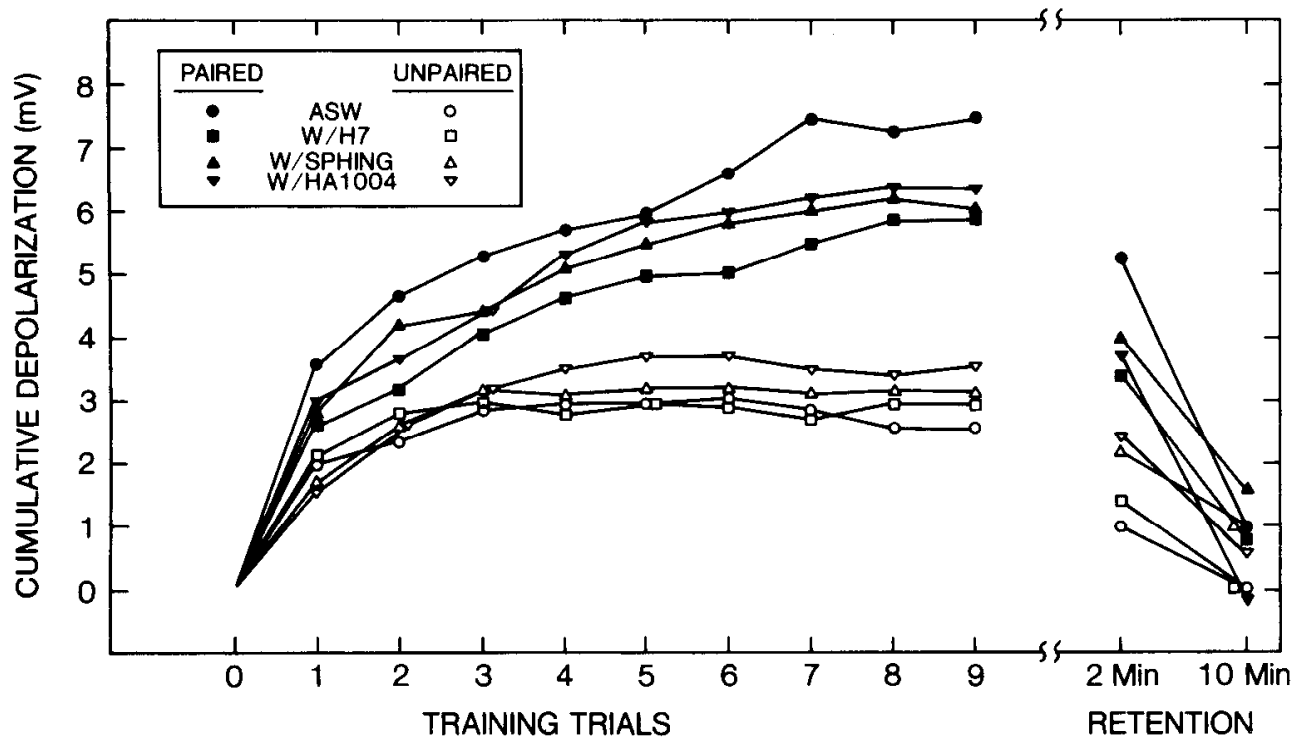

Figure 6. Mean accumulation of depolarization during paired or unpaired presentations of light and depolarizing current to the isolated $B$ photoreceptor for each of 4 bathing mediums (ASW, or ASW with $\mathrm{H} 7$, sphingosine, or HA1004 added). Membrane potential was mcasured $20 \mathrm{sec}$ after light offset. The sustained depolarization is presumably mediated by a rise in intracellular $\mathrm{Ca}^{2+}$. Regardless of the bathing medium, pairings resulted in a progressive increase for at least 5 trials for cells exposed to paired stimuli. In contrast, the weaker accumulation was largely complete after the second trial in cells exposed to unpaired stimuli. Following the last pairing, the depolarization was still evident 2 min later but had dissipated by $10 \mathrm{~min}$ in all groups.
These observations were validated by statistical tests. A 3-factor ANOVA of treatment (paired or unpaired), bathing medium (ASW, H7, sphingosine, or HA 1004), and time of observation (before conditioning, $2 \mathrm{~min}$ after conditioning, or 10 min after conditioning) was conducted. No main effects of treatment or bathing medium were found, indicating that the drugs employed had no effect on the baseline resistance of the cells. A main effect of time of observation was observed $[F(2,72)=$ $6.36, p<0.01]$. Moreover, time interacted with the type of bathing medium $[F(4,72)=2.67, p<0.05]$ and with treatment $[F(2,72)=14.55, p<0.001]$. Finally, a treatment $\times$ medium $\times$ time interaction was observed $[F(6,72)=4.29, p<0.001]$. These interactions indicate that, although the groups had initially comparable levels of resistance, resistance increased as a function of CS-US pairings relative to when the CS and US were unpaired. However, this effect was dependent on the solution in the bathing medium, as the increase in resistance was attenuated by $\mathrm{H} 7$ and sphingosine, but not HA1004.

In the intact, isolated nervous system, pairings of light and rotation produce cumulative depolarization of the B photoreceptor (Alkon, 1980). A strong, progressive depolarization was observed in the present experiment during light-current pairings, but a weaker depolarization was observed if the light and current injections were unpaired. These results are plotted in Figure 6 as a function of conditioning trials and retention interval for cells having received either paired or unpaired light and current presentations in each of the 4 bathing mediums. It is conceivable that $\mathbf{H} 7$ or sphingosine attenuated conditioning by disrupting this cumulative depolarization. This, however, was not the case, as comparable levels of cumulative depolarization were observed in all groups exposed to light-current pairings, as was the weaker depolarization in the groups exposed to light and current unpaired. An ANOVA was conducted on the resting membrane potentials of cells exposed to the paired and unpaired regimen immediately prior to the first stimulus exposure, $20 \mathrm{sec}$ after the final stimulus exposure, 2 min after the final final exposure, and $10 \mathrm{~min}$ after the final exposure. A significant effect of time of observation was observed $[F(3,108)$ $=114.7, p<0.001]$, as was an interaction of pairings and time of observation $[F(3,108)=7.33, p<0.001]$, but no main effect of pairings ( $F=0.53$ ). These results are indicative of an initially comparable, but a larger, progressively increasing depolarization undergone as a result of pairings of light and current injection, relative to when light and current were unpaired. No main effect of the drug in the bathing medium was observed ( $F$ $=0.18)$, nor did the drug type interact with any other factor ( $F$ $\leq 0.86$ ), indicating that the pairing-induced cumulative depolarization was not affected by the drug in the bath. This latter result suggests that the absence of a resistance increase when conditioning occurred in the presence of $\mathrm{H} 7$ or sphingosine was not a result of an antagonism of $\mathrm{Ca}^{2+}$ influx, but rather an antagonism of $\mathrm{Ca}^{2+}$ interaction with the target kinase.

\section{Discussion}

Two conditioned behavioral responses indicative of associative memory were observed within minutes of the completion of 9 training trials. One response, decreased locomotion, appeared to contain both an associative and a nonassociative component, while the other, foot contraction, was exclusively associative. During the time that the short-term conditioned responses were observed, an increase in resistance of the medial B cell soma membrane was detected in cells that were trained in the isolated nervous systems. The medial B photoreceptor synapses on interneurons that in turn synapse on the motor neurons that control turning toward light (Goh et al., 1985). Other evidence suggests that the medial B cell also synapses on interneurons that mediate foot contraction (Akaike and Alkon, 1980).

Resistance is inversely related to $\mathrm{K}^{+}$channel conductance and directly related to excitability. This conductance decrease influences the magnitude of the LLD following a light step, as well as the steady-state light response ( $\Lambda$ lkon, 1984). Each of these responses to light were elevated as a result of light-rotation pairings in the present experiments.

Although a nonassociative influence on locomotion was observed 2 min after conditioning, this response did not appear to arise from the medial $\mathrm{B}$ cell, as unpaired exposure to light and rotation did not affect the properties of this cell relative to cells that received no exposure to these stimuli. Since no nonassociative effects of conditioning on the B cell were observed even in the presence of a nonassociative behavioral response, 
it would appear that in this system, associative learning, as it occurs in the B cell, is not an enhancement of a nonassociative process.

Conditioning of the isolated nervous system, as well as in vitro conditioning of the isolated B ccll, indicatcd that protein phosphorylation, initiated by a cumulative depolarization of the $B$ cell (and probably the associated $\mathrm{Ca}^{2+}$ influx), regulated the acquisition of the memory. Memory was indexed by enhanced steady-state response to light, as well as an enhanced LLD after the offset of the light and/or increased input resistance. These correlates of memory were blocked by sphingosine, which competes with diacylglycerol for the activation of PKC, and $\mathrm{H}$, which inhibits the activity of the kinase. This result suggests the possibility than an initial biochemical step in the memory acquisition is the translocation of $\mathrm{PKC}$ from the cytosol to the membrane, where phospholipid, a critical cofactor for its activation, is present (Hannun et al., 1986). In the membrane, phosphorylation of ion channels or associated proteins may result in an increase in neuronal excitability (cf., Alkon et al., 1988). That a $\mathrm{Ca}^{2+}$-dependent protein kinase (PKC or CaM kinase), as opposed to $\mathrm{c} \Lambda \mathrm{MP}$-dependent kinase, regulated this process was demonstrated by the inability of $\mathrm{HA} 1004$ to attenuate the effects of in vitro conditioning. Our implication of PKC in this process is consistent with a report by Crow et al. (1989) that chronic down regulation of $\mathrm{PKC}$ retards the acquisition of neural correlates of memory in an in vitro conditioning preparation.

It is possible that cAMP-dependent protein kinase plays a role in memory acquisition in vivo if synaptic interactions are required for its activation (e.g., Schachter et al., 1988; for related data, see Grover et al., 1989). Nevertheless, a $\mathrm{Ca}^{2+}$-dependent kinase appears to be an important regulator of the process underlying the cumulative depolarization-induced formation of memory. Since the magnitudes of the resistance increases were similar whether conditioning was performed on the intact nervous system with the CS and US or simulated in the isolated eye, the in vitro simulation employed here may initiate many of the same processes as does conditioning of the intact nervous system with natural CS and US.

As previously described, a wealth of indirect evidence has implicated $\mathrm{Ca}^{2+}$-dependent protein kinase activity in the storage (i.e., at least $24 \mathrm{hr}$ ) of associative memory in Hermissenda. This evidence includes the analogous biophysical effects on the B cell of conditioning with those induced by activation of C-kinase by phorbol ester and/or direct injection of PKC in conjunction with $\mathrm{Ca}^{2+}$ elevation. Here, we report direct evidence that inhibition of PKC and/or CaM kinase blocks the biophysical correlates of memory induction, suggesting that protein kinase activity regulates both the short-term induction and the longerterm maintenance of the associative memory. Related to this latter point, we have recently found that $1 \mathrm{~d}$ after light-rotation pairings, membrane-bound PKC activity, as indexed by tritiated phorbol ester binding, is elevated in the medial and intermediate B cells (D. L. McPhie, L. D. Matzel, J. L. Olds, A. W. Kuzirian, and D. L. Alkon, unpublished observations).

An NMDA-mediated rise in intracellular $\mathrm{Ca}^{2+}$, accompanied by an activation of $\mathrm{PKC}$, has been implicated in the induction of LTP in the rabbit hippocampus (e.g., Malenka et al., 1986; Malinow et al., 1988; but see Muller et al., 1988). Like the results reported here, Malinow et al. (1988) found that $\mathrm{H} 7$ and sphingosine blocked the induction of LTP, while IIA1004 was largely ineffective. Consistent with the hypothesis that $\mathrm{H} 7$ inhibits the activity of PKC, Malinow et al. (1988) also reported that es- tablished LTP could be reversed by the application of $\mathrm{H} 7$ but not by sphingosine, which would affect only the activation of the kinase. We have also found that application of $\mathrm{H} 7$ within 2 min of the completion of conditioning results in at least a partial reversal of the elevated resistance arising from in vitro conditioning in Hermissenda (L. D. Matzel and D. L. Alkon, unpublished observations). These observations therefore suggest a possible conservation of aspects of the neural mechanisms supporting LTP in rabbits and classical conditioning in Hermissenda.

\section{References}

Akaike T, Alkon DL 1980) Sensory convergence on central visual neurons in Hermissenda. J Neurophysiol 44:501-513.

Alkon DL (1979) Voltage-dependent calcium and potassium ion conductances: a contingency mechanism for an associative learning model. Science 205:810-816.

Alkon DL (1980) Membrane depolarization accumulates during acquisition of an associative behavioral change. Science 210:1375-1376.

Alkon DL (1984) Calcium-mediated reduction of ionic currents: a biophysical memory trace. Science 226:1037-1045.

Alkon DL (1989) Memory storage and neural systems. Sci Am 260: $42-50$.

Alkon DL, Farley J, Sakakibara M, Hay B (1984) Voltage-dependent and calcium-activated potassium currents of a molluscan photoreceptor. Biophys J 40:605-614.

Alkon DL, Kubota M, Neary JT, Naito S, Coulter D, Rasmussen H (1986) C-kinase activation prolongs $\mathrm{Ca}^{2+}$-dependent inactivation of $\mathrm{K}^{+}$currents. Biochem Biophys Res Commun 134:1245-1253.

Alkon DL, Naito S, Kubota M, Chen C, Bank B, Smallwood J, Gallant $\mathrm{P}$, Rasmussen $\mathrm{H}$ (1988) Regulation of Hermissenda $\mathrm{K}^{+}$channels by cytoplasmic and membrane-associated C-kinase. J Neurochem 51: 903-917.

Connor J, Alkon DL (1984) Light- and voltage-dependent increases of calcium ion concentration in molluscan photoreceptors. J Neurophysiol 51:745-752.

Crow T (1983) Conditioned modification of locomotion in Hermissenda crassicornis: analysis of time-dependent associative and nonassociative components. J Neurosci 3:2621-2628.

Crow 'I, Alkon DL (1978) Retention of an associative behavioral change in Hermissenda. Science 201:1239-1241.

Crow T, Forrester J, Waxham N, Neary J (1989) Effect of down regulation of protein kinase $\mathrm{C}$ on short-term enhancement of generator potentials in Hermissenda produced by light and 5-HT. Soc Neurosci Abs 15:1284

Farley J (1988) Associative training results in persistent reductions in a calcium-activated potassium current of Hermissenda Type B photoreceptors. Behav Neurosci 102:784-802.

Farley J, Auerbach S (1986) Protein kinase C activation induces conductance changes in Hermissenda photoreceptors like those seen in associative learning. Nature 319:220-223.

Farley J, Richards WG, Ling LJ, Liman E, Alkon DL (1983) Membrane changes in a single photoreceptor cause associative learning in Hermissenda. Science 221:1201-1203.

Goh Y, Lederhendler I, Alkon DL (1985) Input and output changes of an identified neural pathway are correlated with associative learning in Hermissenda. $\mathrm{J}$ Neurosci 5:536-543.

Grover LM, Farley J, Vold L (1987) Training and testing determinants of short-term associative suppression of phototaxic behavior in $\mathrm{Her}$ missenda. Behav Neur Biol 47:275-306.

Grover LM, Farley J, Auerbach SB (1989) Serotonin involvement during in vitro conditioning of Hermissenda. Brain Res Bull 22:363372.

Hannun YA, Loomis CR, Merrill AH, Bell RM (1986) Sphingosine inhibition of protein kinase $\mathrm{C}$ activity and of phorbol dibutyrate binding in vitro and in human platelets. J Biol Chem 261:1260412609.

Hidaka H, Inagaki M, Kawamoto S, Sasaki Y (1984) Isoquinolinesulfonamides, novel and potent inhibitors of cyclic nucleotide dependent protein kinase and protein kinase $C$. Biochemistry 23:50365041.

Jefferson AB, Schulman H (1988) Sphingosine inhibits calmodulindependent enzymes. J Biol Chem 263:15241-15244. 
Kandel ER, Klein M, Castellucci VF, Schacher S, Goelet P (1986) Some principles emerging from the study of short- and long-term memory. Neurosci Res 3:498-520.

Keppel G (1982) Design and analysis: a researchers handbook. New Jersey: Prentice Hall.

Lederhendler II, Gart S, Alkon DL (1986) Classical conditioning of Hermissenda: origin of a new response. J Neurosci 6:1325-1331.

Levitan IB (1985) Phosphorylation of ion channels. J Membr Biol 87 : 177-190.

Lisman JE, Goldring MA (1988) Feasibility of long-term storage of graded information by the $\mathrm{Ca}^{2+} /$ calmodulin-dependent protein kinase molecules of the postsynaptic density. Proc Natl Acad Sci USA 85 : 5320-5324.

Malenka RC, Madison DV, Nicoll RA (1986) Potentiation of synaptic transmission in the hippocampus by phorbol esters. Nature 321:175177.

Malinow R, Madison DV, Tsien RW (1988) Persistent protein kinase activity underlying long-term potentiation. Nature 335:820-824.

Matzel LD, Schreurs B, Lederhendler I, Alkon DL (1990a) Acquisition of conditioned associations in Hermissenda: additive effects of contiguity and the forward interstimulus interval. Behav Neurosci (in press).

Matzel LD, Schreurs B, Alkon DL (1990b) Pavlovian conditioning of distinct components of Hermissenda's responses to rotation. Behav Neur Bio (in press)
Muller D, Turnbull J, Baudry M, Lynch G (1988) Phorbol esterinduced synaptic facilitation is different than long-term potentiation. Proc Natl Acad Sci USA 85:6997-7000.

Naito S, Bank B, Alkon DL (1988) Transient and persistent depolarization-induced changes of protein phosphorylation in a molluscan nervous system. J Neurochem 50:704-711.

Neary JT, Crow T, Alkon DL (1981) Change in a specific phosphoprotein band following associative learning in Hermissenda. Nature 293:658-660.

Nelson TJ, Alkon DL (1989) Specific protein changes during memory acquisition and storage. Bioessays 10:75-79.

Nelson TJ, Collin C, Alkon DL (1990) Isolation of a G protein that is modified by learning and reduces potassium currents in Hermissenda. Science 247:1479-1483.

Schachter S, Castellucci VF, Kandel ER (1988) cAMP evokes longterm facilitation in Aplysia sensory neurons that requires new protein synthesis. Science 240:1667-1669.

Schwartz JH, Greenberg SM (1987) Molecular mechanisms for memory: second-messenger induced modifications of protein kinases in nerve cells. Annu Rev Neurosci 10:459-476.

West A, Barnes E, Alkon DL (1982) Primary changes of voltage responses during retention of associative learning. J Neurophysiol 48: $1243-1255$. 